Chapman University

Chapman University Digital Commons

3-1-2011

\title{
Father Death and Adult Success Among the Tsimane: Implications for Marriage and Divorce
}

\author{
Jeffrey Winking \\ Texas A\&M University \\ Michael Gurven \\ University of California, Santa Barbara \\ Hillard Kaplan \\ Chapman University, hkaplan@chapman.edu
}

Follow this and additional works at: https://digitalcommons.chapman.edu/esi_pubs

Part of the Biological and Physical Anthropology Commons, Economic Theory Commons, Ethnic Studies Commons, Latin American Studies Commons, Other Anthropology Commons, Other Economics Commons, and the Social and Cultural Anthropology Commons

\section{Recommended Citation}

Winking, J., Gurven, M., \& Kaplan, H. (2011). Father Death and Adult Success among the Tsimane: Implications for Marriage and Divorce. Evolution and Human Behavior, 32(2), 79-89. https://doi.org/ 10.1016/j.evolhumbehav.2010.08.002 


\title{
Father Death and Adult Success among the Tsimane: Implications for Marriage and Divorce
}

\author{
JEFFREY WINKING \\ Department of Anthropology, Texas A\&M University \\ MICHAEL GURVEN \\ Department of Anthropology, University of California-Santa Barbara \\ HILLARD KAPLAN \\ Department of Anthropology, University of New Mexico
}

\section{Introduction}

\begin{abstract}
Human fathers are heavily involved in the rearing of children around the world. While there is great cross-cultural variation, the father is a recognizable role in all populations. This deviates from the standard mammalian pattern of little paternal investment. A logical explanation offered early by evolutionary theorists is that human fathers evolved the capacity for paternal concern because human children are remarkably needy and impose a great encumbrance on the mother (Lancaster \& Lancaster, 1983; Lovejoy, 1981). Thus, fathers have greater opportunity to enhance the wellbeing of child and mother, as there is a deeper well of need to fill. Marginal gains of family investment are thus steeper, leading to greater possibility for such returns to supersede those provided by the short-term mating strategies that are typical of most mammals. However, the numerous studies that have explored the cross-cultural impact of father presence on child survivorship report mixed results (Sear \& Mace, 2008), indicating that father presence (and by assumption, investment) does not universally associate with better-off children.
\end{abstract}

Fathers may also play an important role in enhancing the future competitiveness of their children by enhancing their physical condition, teaching them important skills, accumulating heritable wealth, or by building social alliances (Hewlett, 1992; Scelza, 2010). Previous studies have largely focused on the wellbeing of juvenile children, but a more complete test of the impact of paternal investment concerns its effect on the reproductive value of children, which must include adult fertility. Our goal in this paper is to fill this gap in the literature by reporting several measures of achieved success of adults based on the number of years their fathers were alive and present during their childhood. Specifically, we explore the impact of father presence on offspring height, body mass index (BMI), age of first reproduction, completed fertility for age, and number of surviving children for age. We report only one significant finding out of ten specific tests (five predictions for both men and women), thus failing to find any robust pattern of father death impacting the achieved

(C) 2010 Elsevier Inc. All rights reserved

All correspondence should be sent to: Jeffrey Winking Department of Anthropology Texas A\&M University 4352 TAMU College Station, TX 77843-4352 jwinking@tamu.edu.

Publisher's Disclaimer: This is a PDF file of an unedited manuscript that has been accepted for publication. As a service to our customers we are providing this early version of the manuscript. The manuscript will undergo copyediting, typesetting, and review of the resulting proof before it is published in its final citable form. Please note that during the production process errors may be discovered which could affect the content, and all legal disclaimers that apply to the journal pertain. 
success of adult children. Finally, we relate our findings to the nature of Tsimane marriage. Marriage in humans is often considered a means of facilitating the providing of bi-parental care (Hurtado \& Hill, 1992; Lovejoy, 1981). Among the Tsimane, marriages are fairly stable, particularly after children have been born, strengthening the prediction that the presence of Tsimane fathers should be important to the success of children. We thus explore alternative explanations for the stability of Tsimane marriages by examining alternative fitness pathways and constraints experienced by Tsimane men.

\subsection{Paternal Care in Humans}

Paternal care is rare among mammals, a class in which females are biologically obliged to provide the bulk of investment throughout gestation and lactation. This leaves less opportunity for males to make a difference. Paternal care is more common among primates in which offspring are born more altricial and require an extended period of dependence (Kleiman \& Malcolm, 1981). Even among primates, however, substantial paternal provisioning and care is largely limited to small New World primates and humans. Furthermore, levels of body size sexual dimorphism among Australopithecines, an indicator of the intensity of male-male competition and rates of polygyny, are more similar to those of other apes (Plavcan, et al., 2005; Plavcan \& Van Schaik, 1997). Thus, it is unlikely that long-term pair-bonds and high levels of paternal investment existed as ancestral traits, which has motivated the search for selection pressures that resulted in the exceptional mating systems and reproductive strategies observed in humans.

Evolutionary theorists originally attributed men's capacity for paternal and long-term romantic involvement to the greater ability of men to enhance child wellbeing. Very young children are quite helpless, greatly impeding a mother's ability to forage (Hurtado, et al., 1992; Marlowe, 2003). As children grow, they remain economically dependent until their late teens (Kaplan \& Lancaster, 2003; Lee \& Kramer, 2002). Despite the high levels of dependency of human children, however, women are able to maintain inter-birth intervals that are significantly shorter than those observed in other great apes (Alvarez, 2000). Such a system can only be maintained with supplementary labor and/or resources, and many have argued that men, as husbands and fathers, act to partly fill this role. This line of reasoning, referred to as the provisioning model, posits that the greater need of women and children yields steeper marginal fitness gains for paternal investment than could be obtained from alternative mating and investment strategies. Additionally, this model holds that the universal practice of marriage functions to facilitate the provisioning of bi-parental care (Lancaster \& Lancaster, 1983). The sexual exclusivity (or at least regulations) allows men the opportunity to invest in children they know to be their own, while the nuclear family can take advantage of cooperative synergies, such as divisions of labor and the exploiting of economies of scale (Gurven \& Hill, 2009).

While many have called into question the ultimate functions of men's investment decisions (Bleige Bird, et al., 2001; Hawkes, 1991, 1993; van Schaik \& Paul, 1996), research in numerous populations has shown that substantial paternal investment is a typical feature of human families (e.g., Anderson, et al., 1999; Hewlett, 1992; Marlowe, 2005; Winking, Gurven, et al., 2009). If men invest in their children, then commensurate costs should be detectable upon the loss of a father to death, divorce or desertion. While other interested kin members may boost their investments to make up for the loss of a parent, men pay no costs for this compensation (if they are unrelated to the helping kin). Therefore, if there is no net benefit to children, after accounting for the compensatory help, there would have been no selection for greater paternal involvement via the pathway of enhanced offspring condition (Blurton Jones, et al., 2000). 
The impact of paternal presence, however, is not always observed. While all studies that have explored the impact of maternal absence on child survivorship among natural fertility populations report a significant effect, only seven of 22 studies found a significant positive effect of father presence on child survivorship. Among the Tsimane, a significant effect was found for children whose fathers died prior to age 5, although it was less substantial than the effect of mother death (Table 1) (Winking, et al., n.d.).

Apart from the focus on offspring survivorship, an extensive literature suggests that father absence increases the likelihood of child delinquency, psychological problems, and poor academic performance among Western families (reviewed in Lamb, 1997). One cannot know, however, the degree to which such effects would have direct impacts on adult fitness. The few studies exploring continuous measures of child wellbeing among natural fertility populations have reported mostly null results. For example, no significant differences were reported between the height and weight of children living with biological fathers versus those living without them among the Yanomamö (Hames, et al., no date) or a rural Gambian population (Sear, et al., 2000). Yanomamö children of divorced or junior mothers were more likely to be found with ectoparasite infection (Hagen, et al., 2001), although no other significant differences were found in morbidity levels (Hames, et al., no date).

Effects of paternal involvement may not be limited to childhood, however. In order to assess the complete fitness benefits conferred to children due to paternal behavior, outcomes of adult children must also be measured. Fathers play important roles in the socialization of their children (Hewlett, 1992; Schniter, 2009), and are often involved in facilitating marriage for their children (Apostolou, 2008; Hartung, 1982; Scelza, 2010). Fewer studies, however, have explored the impact of paternal presence on indicators of success among adult children. In Western populations, being raised in mother-only families is associated with lower financial outcomes as an adult (Lang \& Zagorsky, 2001; McLanahan \& Sandefur, 1994; Powell \& Parcel, 1997). Children of divorced parents more frequently report psychological problems as adults (Cherlin, et al., 1998), lower marital satisfaction and are more likely to be divorced (Amato, 1996; Bumpass, et al., 1991). Two studies exploring non-Western populations have reported positive effects of the presence of biological fathers on the marital and reproductive success of children among a Dominican (Flinn, 1988) and Australian Aboriginal (Scelza, 2010) population. Aside from these two studies, all others exploring adult effects among natural fertility populations have focused on testing the Psychosocial Stress Hypothesis, which suggests that children somehow adjust their rates of maturation based on the socioecological context in which they are raised (Belsky, et al., 1991). Many tests have investigated (and confirmed) the association between parental divorce or father absence and earlier ages of menarche, first sexual activity and first reproduction (reviewed in Ellis, 2004). Because development and maturation is typically delayed by nutritional stress, such findings are actually contrary to what would be expected by the removal of men's investment. More than likely, two separate proximate pathways are at work.

Regardless of the pace of maturation, children from fatherless households should still fare more poorly than those from two-parent households. Unfortunately, such studies tend to focus solely on the age of first occurrence of numerous milestones and not on continued success.

\subsection{Predicted Impacts of Father Death on Adult Success}

There are numerous pathways by which fathers might impact the success of their adult children. (Hypothesis 1) If children with living fathers enjoy higher levels of provisioning throughout childhood, they should attain greater adult body size, which can have a positive impact on adult fertility rates (Charnov \& Berrigan, 1993; Hill \& Hurtado, 1996; Sear, et al., 2004). Adult height is highly heritable in well-nourished populations, but less so in energystressed populations where social circumstances, pathogen stress and nutritional factors play 
larger roles in determining height (Silventoinen, et al., 2000). In such populations, completed height is often associated with economic or social status during childhood (Nystrom Peck \& Lundberg, 1995). Among the Tsimane, in which close to half of all children are considered stunted (Foster, et al., 2005), it is very likely that children are not reaching their maximal height and are limited by energy availability. We thus predict that height will be negatively associated with the number of years of one's childhood spent with both parents (Prediction 1).

Body mass index (BMI), on the other hand, is a cumulative measure of more recent energetic balance. Fathers often play an important role in the development of skills, social networks and status necessary to more efficiently extract resources or secure larger portions of them (Hewlett, 1992; Schniter, 2009). The loss of a father should thus result in greater nutritional stress as an adult as well. Thus we predict a negative relationship between childhood years with father and adult BMI (Prediction 2).

The expected effect of father presence on age of first reproduction (Hypothesis 2) is less clear as the psycho-social stress hypothesis (and previous empirical trends) suggests an earlier age of reproduction, while a reduction in overall investment should lead to delayed development, as well as delayed access to knowledge and resources that might be necessary to obtain a partner, especially for sons. We can predict, however, a negative association between years with father and the probability of adults ever reproducing (Prediction 3), particularly for men, who experience greater variance in reproductive success. While individuals typically have some autonomy in choosing marital partners, parents often play a role in arranging suitable matches. The Tsimane prefer cross-cousin marriage (i.e. marrying the child of one's mother's brother or father's sister), and opposite-sexed siblings will often enter into a system of arranging marriages between their respective children. When clear, culturally preferred choices are not available, having a father might expand a son's social kin-network from which to choose a spouse and increase the wealth he has available to him to enhance his competitiveness. Fathers might also play a role in ensuring high quality suitors for their daughters. Indeed, evidence on 622 marriages shows that fathers helped a son or daughter obtain a spouse in over a third $(36 \%)$ of the cases.

Finally, the combined effects of larger adult body size, greater foraging and social skills and capital and greater likelihood of marriage and reproduction should lead to augmented fertility rates among individuals whose fathers did not die during childhood (Hypothesis 3). Father death also eliminates the possibility of continued parental and grandpaternal investment later in life. Therefore, we predict the number of childhood years an individual's father was alive to be positively associated with the total number of live births (Prediction 4) and the number of surviving children (Prediction 5).

\section{Methods}

\subsection{Population}

The Tsimane are a forager-horticultural population living primarily along the Maniqui River, and its tributaries east of the Andean foothills in central lowland Bolivia. They number less than 10,000 and reside in some 80 villages, each consisting of multiple extended families (Gurven, et al., 2007). Related families build their houses close together forming well defined household clusters. The Tsimane derive the majority of their calories from family-maintained fields consisting mainly of rice, plantains, corn and sweet manioc. Agricultural food is supplemented with wild game, fish, foraged fruits and market goods (whose level varies by proximity to local towns and merchants). 
Marriages are mostly monogamous (90-95\% of married men) and relatively stable, with roughly $20 \%$ of marriages ending in divorce (Winking, et al., 2007). Parents often play some role in the marital choice of their children, and there appears to be stronger influence placed on the marital decisions of daughters compared to sons (Gurven, et al., 2009). Families of opposite-sex siblings will often pair off many of their respective children, although the children can and do pursue alternatives. If no partner is evident at the time a man comes of age, he will pursue opportunities in other villages. Men will often approach the house of a potential bride and engage in a short period of courtship lasting a few weeks. During this time, his suitability is assessed by the woman and her family. There is no formal ceremony, and a couple is considered to be married when they start coresiding in the same house. It is customary for newly formed couples to live with the wife's family for the first few years of marriage, after which they are free to choose where they wish to live.

When divorce does occur, it often is the result of men failing to return from extended wagelabor forays or either the husband or wife "escaping" to other villages (often returning to natal villages). It is rare for fathers or paternal kin to be left with children following divorce. Children of divorced families are often raised by mothers and then by maternal kin after a mother's remarriage. Step-parent families are thus relatively rare among the Tsimane. Similar practices follow the death of the spouse. Death of a spouse is not uncommon, with nearly $40 \%$ of individuals reaching 20 years of age dying before age 55 (Gurven, et al., 2007). Infectious disease accounts for roughly $50 \%$ of deaths in early adulthood and $60 \%$ in middle adulthood, while violence and accidents account for roughly a fourth of mortality (ibid.)

Men and women spend roughly equal amounts of time in the production of agricultural goods, which are largely consumed within the nuclear family, but also shared among nearby related households. Men are the main providers of game and fish, both of which are often communally eaten by extended families when acquired in large amounts. Men also earn nearly all of the wages brought into the house. Women spend the bulk of their day in camp and are responsible for the majority of childcare, with mothers spending nearly 10 times as much time in direct parenting as fathers (Winking, Gurven, et al., 2009). Women are also largely responsible for food processing and domestic tasks (Gurven, et al., 2009).

\subsection{Years of Birth, Death and Father Absence}

Demographic interviews were collected on all available adults in 21 villages from 2002 through 2005, although we have continued to collect demographic information on individuals who reside in the sample communities. These interviews included the reproductive histories of the individual being interviewed, his or her parents and siblings. This resulted in the identification of 6,795 individuals for whom birth years and, if necessary, death years were estimated. A number of methods were employed to estimate the timing of births and deaths. These included using well known dated events, relative age lists, known ages from written accounts, photo comparisons of people with known ages, and cross-validation of information from independent interviews of kin. Methods are described at length in Gurven et al. (2007).

Father absence is measured as the number of years the father was alive and married to the mother of the child until the $20^{\text {th }}$ year of life for anthropometrics (approximately the age of cessation of growth for later-developing men) and $15^{\text {th }}$ year of life for fertility measures (approximately the earliest age of reproduction for earlier-reproducing women). Children of divorced parents are not included because the data did not allow for determination of postdivorce residence or paternal contribution to parenting and provisioning. Individuals were excluded if the birth or death years of either parent were unknown or if the parents had divorced. Parents were considered divorced if either parent had a subsequent child with 
another partner or if the parents were recorded in different families. If the parents of an individual had no subsequent children and their current family membership was unknown, they were considered married if more than 10 years had transpired since the birth of the individual and the mother was age 35 or above at the time of birth. Otherwise, the individual was excluded.

\subsection{Anthropometrics}

Height and weight were measured by a medical team that visited each community in the research sample one to two times per year, from 2002 through 2009. Height was measured using a portable SECA stadiometer. Weight was measured using a Tanita digital weigh scale. Only the most recent (non-pregnant for women) measures were used in analyses. We limited the sample to those who were 20 yrs of age or older, resulting in a sample of 392 women and 404 men. Within these samples, $83(21 \%)$ women and $73(18 \%)$ men had a father die prior to age 20, $35(9 \%)$ and $33(8 \%)$ before age 10 , and $15(4 \%)$ and $19(5 \%)$ before age 5 (respectively).

\subsection{Statistical Analysis}

For continuous dependent measures (height, BMI, fertility) general linear models were used, including controls for age, sex, and geographic region. For age of first reproduction, a Cox proportional hazards model was employed. The terminal year for each individual was set as the year of first reproduction. If the individual had not yet reproduced, the terminal year was set as the year of the interview or the last year in which he or she resided in a sample community. A dichotomous variable represented whether or not the individual had reproduced. Sex and community region were included in the model as controls. Analyses were conducted using SPSS 17.0 and SAS 9.2.

\section{Results}

\subsection{Father Death and Completed Height and Adult BMI}

Average height was $162.65 \mathrm{~cm}$ for men $(\mathrm{N}=404, \mathrm{SD}=5.39,95 \% \mathrm{CI} 162.12-163.17)$ and $151.09 \mathrm{~cm}$ for women $(\mathrm{N}=392, \mathrm{SD}=4.92,95 \% \mathrm{CI} 150.60-151.57)$. Table 2 displays the completed heights of individuals whose fathers died from ages 0 to 9 and from ages 10 to 19 compared to those whose fathers were alive for the first 20 years of life. The means reported are estimated marginal means after controlling for age (which negatively correlates with height) and community region. No significant differences were found in the predicted direction. There was also no effect of father presence on completed height when using the number of years as a continuous variable in a general linear model (Table 3 ).

Average BMI for the sample was 23.31 for men $(\mathrm{N}=404, \mathrm{SD}=2.11,95 \%$ CI 23.10 - 23.52) and 23.15 for women $(\mathrm{N}=392, \mathrm{SD}=3.03,95 \%$ CI $22.84-23.45)$. Men who lost a father in late childhood actually exhibited higher BMI than those whose fathers remained alive $(\mathrm{t}=1.979, \mathrm{~N}=371, \mathrm{P}=0.049)$. There was one significant effect in the predicted direction: women whose fathers died prior to age 10 had a lower BMI $(\mathrm{t}=-2.799, \mathrm{~N}=344, \mathrm{P}=0.005)$ (Table 2). Unlike the effect found with men's BMI, this effect held when using a continuous measure of father presence, such that every 10 years of father presence translates to a 0.78 increase in adult $\mathrm{BMI}(\mathrm{F}=5.328, \mathrm{~N}=392, \mathrm{P}=0.012)$ (Table 3).

The $80 \%$ sensitivity for these tests was $\mathrm{f}^{2}=0.015$ for men and 0.016 for women (for both height and BMI), which are below the commonly-used cutoff for "small" effect size of $\mathrm{f}^{2}=0.02$ (Cohen, 1992). The ceiling effect imposed by the maximum age the father could be alive during childhood ( 20 years) obviously reduces the actual power of these tests. If we were to only include those individuals (of both sexes) who lost a father prior to age 20 , the 
overall sensitivity would be $\mathrm{f}^{2}=0.040$. Thus, we can be fairly confident in asserting the null for even a relatively small effect. Including a random term in the general linear model for family did not change any non-significant results for either height or BMI. The random term did, however, cause the impact of father death on women's BMI to become non-significant. This indicates that within families, younger daughters who spent more of their childhood without a father do not exhibit lower BMI compared to their older sisters, who spent more time growing up with their father. The disappearance of the effect might indicate some heritable correlation between BMI and susceptibility to disease (i.e. lower BMI is indicator of father's mortality risk). It might also simply be due to the fact that within-family covariance in BMI accounts for so much variation that little is left to be explained.

\subsection{Father Death and Age of First Birth}

The median age of first birth of this sample was 23 for men and 19 for women. Figure 1 displays the median age of first birth by age at father's death. While there appears to be a general trend of earlier first birth for sons as the number of years that a father was alive decreases, a Cox proportional hazards analysis indicates no significant effect for either sex (Table 4). Because there is reason to expect an increase in the hazard for first birth for earlier ages among those who lost their fathers (based on the Psychosocial Stress Hypothesis), but perhaps no effect or even a reversal of the trend for this group at later ages, we divided the sample into two based on the median age of first reproduction for men and women. There were no significant effects of years that father was alive on age of first birth for early or late reproducers.

There was no greater likelihood of failing to reproduce by age thirty for sons of deceased fathers. Ninety percent $(\mathrm{N}=233)$ of sons whose fathers did not die prior to age 15 were able to reproduce by age 30, while $91 \%(\mathrm{~N}=44)$ of sons whose fathers died before age 15 reproduced by age 30 (Fisher Exact, $\mathrm{P}=1.000$ ). For daughters who reproduced by 25 , the figures are $93 \%(\mathrm{~N}=254)$ and $92 \%(\mathrm{~N}=39)$ respectively (Fisher Exact, $\mathrm{P}=1.000)$. Using univariate logistic regression models, there was no significant effect of the continuous age at father's death and the probability of failing to reproduce by age 30 for men $(B=-0.008$, $\mathrm{N}=277, \mathrm{P}=0.887)$ or by age 25 for women $(\mathrm{B}=0.040, \mathrm{~N}=293, \mathrm{P}=0.543)$.

\subsection{Father Death and Fertility for Age}

No significant effect was found when regressing number of live births on age at father's death and age for men $(\mathrm{B}=0.008, \mathrm{t}=0.17, \mathrm{P}=0.865)$, or for women $(\mathrm{B}=-0.026, \mathrm{t}=-0.59$, $\mathrm{P}=0.554$ ) (Table 5). Including only children who lived to age 10 or are currently alive and less than 10 did not change this result (Table 5). The 80\% sensitivity of these analyses is below the commonly-used cutoff for "small" effect size of $0.2\left(\mathrm{f}^{2}=0.011\right.$ for men and women). Including a random term for family did not change the significance status of the number of years the father was alive for either men or women.

\section{Discussion}

Of the five predictions concerning the impact of father death on different measures of offspring wellbeing and success (height, BMI, age of first reproduction, completed fertility for age, surviving children for age), only women's BMI was found to be negatively impacted by the death of a father during childhood. We thus failed to find any robust pattern of father death during childhood having a negative effect on outcomes of adult wellbeing. While one significant effect of eight tests may not constitute a pattern, it is important to note that the effect on BMI did maintain significance even after considering a Bonferroni adjusted $\alpha$ of 0.0063 for the categorical age variable $(\mathrm{P}=0.005)$ and maintained one-tailed significance for the continuous measure $(\mathrm{P}=0.012)$. 
The most direct fitness outcome presented in this study is completed fertility for age. If the capacity for paternal involvement was selected because of the positive impact it had on offspring success, this success must ultimately be in the form of greater survivorship and/or fertility (i.e. reproductive value). We have previously shown that men's presence does have a positive impact on the survivorship of children (Winking, et al., n.d.). The data presented here, however, suggests that fatherless children who do survive reproduce at a similar rate compared to those who were raised by both parents.

The lack of substantial effects is surprising among a high mortality group like the Tsimane, in which fathers play a substantial role in family provisioning and in which male-initiated divorce is rare after the birth of the first few children (Kaplan, et al., In press). The degree to which these conditions mirror the situation in which the capacity for marital and paternal involvement evolved in men is unknown. Compared to fathers in horticultural populations, those in foraging populations tend to be more involved in their children's care and responsible for greater proportion of direct production (Marlowe, 2000). But unlike the maternal relationship, paternal involvement and the impact of this involvement vary widely across populations (Sear \& Mace, 2008). Thus, it is clear that men have a capacity to engage in a wide range of long-term sexual strategies and levels of paternal involvement. If we expect men to respond flexibly to local conditions, this poses somewhat of a conundrum. Why should Tsimane men stay when others are willing to make up for their absence? Even substantial effects of father absence on child survivorship can be offset by marrying a second spouse that is modestly younger than the first spouse (Winking, Kaplan, et al., 2009). This suggests that even in contexts in which men's care is extremely important, access to additional fertility might often trump the benefits of reduced child mortality.

Obviously, the testing of a population-level prediction by exploring a single population is fraught with the potential for error. Historical forces might overpower socioecological influences, sample conditions might be different from those during which cultural patterns developed, etc. However, such individual analyses are the only way to grow the greater body of cross-cultural data points. Furthermore, those populations that do not fit the expected pattern might provide the greatest insight by revealing important factors omitted from previous models. Below, we offer possible explanations for the observed Tsimane patterns, explanations which will hopefully be explored in greater detail with future research.

Blurton Jones et al (2000) suggested that operational sex ratios were more important than father effects in determining population divorce rates (also see, Pedersen, 1991; Schmitt, 2005). They argue that men in populations with comparatively more women would be more likely to divorce as they would have more opportunity to remarry younger wives, and found a corresponding effect among four foraging populations. The operational sex ratio of our sample communities, calculated as the ratio of men ages 20 to 55 to women ages 15 to 40 , is 1.01 , which would place it in the middle of four foraging populations investigated in the Blurton Jones et al study. Taking into account the total fertility rates of the populations, as Hurtado and Hill (1992) did, increases the apparent benefit of Tsimane men to divorcing even more, despite the Tsimane having one of the lowest divorce rates. The availability of allomaternal caregivers is also associated with pairbond instability cross-culturally (Quinlan \& Quinlan, 2007). Among the Tsimane, when a husband leaves, maternal kin often attend to the abandoned bride and children and offer additional investment, assuredly lessening the negative impact of the father's absence (Winking, 2006). Most Tsimane men stay in marriages and rarely divorce despite the possibility of this allocare. For those men who desert a wife after a child has been born, there is often animosity expressed by the wives and their families, but there is no great social ostracism or acknowledgment that a deep cultural norm has been breached. 
Among the Tsimane, the preference for cross-cousin marriage increases the level of relatedness to in-laws. Such relationships might lead to greater pressure from all sides to remain within a marriage and pose greater costs of divorce in the form of reduced inclusive fitness and strained family relations. This is likely to be the case, however, in most subsistence-living, natural fertility populations in which kinship plays a large role in determining marriage partners. Another possibility is simply temporal sampling error. Perhaps marital norms developed in a time during which child wellbeing was heavily dependent on paternal investment and behavioral strategies and cultural perspectives have not yet responded to new conditions (possible reasons for such resistance are discussed below). Similarly, paternal involvement may only be crucial during intermittent periods of hardship, not sampled in the current study, which might maintain the patterns of marital stability.

Finally, it is possible that men are responding optimally, but that our hypotheses failed to take into account relevant benefits, costs or constraints. Two related points might reconcile the marital stability that men display despite the possibility of higher potential gains from divorce. First, the fitness benefits obtained from remaining in a marriage are not only in the form of enhanced wellbeing of children. The investment that men offer might not result in higher fitness in children, as other caretakers (including the mother) are free to lower their own levels of investment when a father is present. This can result in an overall standard level of investment received, regardless of father investment (Smith \& Fretwell, 1974). If the resources saved by others due to the father's investments are translated into greater couple fertility, then paternal investment can actually be perceived as an investment to increase offspring quantity (Gettler, 2010; Winking, 2006).

While the above logic explains why men might reduce philandering in order to invest parentally, despite an apparent lack of robust father effects, it fails to explain why men do not universally engage in serial monogamy, investing in the fertility of progressively younger wives. To explain this, we consider the second point: men are constrained by the opportunities available to them by the actions of other men and the preferences of women. While previous studies of men's marital decisions often explored the issue solely from the male point of view (Blurton Jones, et al., 2000; Hawkes, et al., 1995; Hurtado \& Hill, 1992), more recent work has considered a two-sex approach (Borgerhoff Mulder, 2009; Quinlan, 2008; Winking, 2006), as have animal models for some time (Lazarus, 1990; Maynard Smith, 1977; Trivers, 1972). Women have much to gain from the investment of men, as do the kin of potential brides, who may have to compensate for the desertion of a son- or brother-in-law. This preference for men's investments should be greater than men's motivations to provide them, as these individuals are not paying the direct or opportunity costs that the investing men must incur. This creates opportunity for conflict and might increase demand for greater assurance of men's intent or a reduced willingness of women to pair with casual philanderers or apparent serial husbands. If such assurance requires the use of some honest (i.e. costly) signaling, the returns to short-term or serial strategies would be diminished, increasing the relative benefit of acquiescing to women's demands. Among the Tsimane, however, the evidence is mixed concerning women's demands for assurance of long-term intent and their impact on men's options. Marriages are not marked by lengthy courtships or extravagant ceremonies, yet never-been-married single mothers are relatively rare.

Other female preferences might play a role in limiting men's marital strategies. In situations in which women have much to gain from monopolizing a greater portion of men's lifetime investments, women may be reluctant to marry much older men who have little remaining production left to invest. This would limit the number of potential alternative spouses to men considering divorce later in life, who might not be considered viable partners to never- 
married women. The median age difference among 610 reproductive pairings was four years, with $58 \%$ of couples being less than five years apart and $87 \%$ being less than 10 years apart.

Finally, low divorce rates might be maintained by the frequency-dependent nature of the viability of divorce as an alternative to marriage. Fewer divorces mean that fewer alternative partners are available to choose from. Therefore, if having a spouse is considered essential, married individuals living in a low-divorce population have few opportunities besides staying within a marriage. Universal marital stability, particularly when paired with a preference for age-matched unions, is a system which therefore may be resistant to invasion by alternative strategies and one which might require substantial socioecological changes to allow for change. Among the Tsimane, this is possibly reflected in the low rates of remarriage (indicated here by continued reproduction) upon the death of a spouse for both women and men (Figure 2). Logistic regression reveals that the effect of a spouse dying on one's probability of reproducing in the next 10 years is substantial (Men, $B=-1.627$, $\mathrm{N}=2386, \mathrm{P}<0.001$; Women, $\mathrm{B}=-1.461, \mathrm{~N}=2385, \mathrm{P}<0.001$ ).

Based on the logic above, a number of predictions can be offered. If women are indeed demanding costly signals of intent, courtship expenditures should be associated with men's marital fidelity, and the magnitude of women's expectations should be negatively associated with men's philandering efforts. While the prediction that individuals should be less likely to divorce in a population with low divorce rates might be a mere tautology, we can predict that individuals should more frequently cite a lack of alternative options as a reason for staying within a less-than-ideal marriage in such populations. Similarly, men in populations in which women demand greater age similarity (thereby reducing the possibility of married men marrying never-been-married women) should exhibit greater marital stability. These predictions are supported by previous studies exploring such issues based on sex ratios (Blurton Jones, et al., 2000; Trent \& South, 1989), although here we suggest that operational sex ratios, which simply consider reproductively available partners, might be more informative if considering socially available partners.

\section{Conclusion}

Among the Tsimane, the positive impact that fathers have on the survivorship of their children has been documented (Winking, et al., n.d.). After reviewing overall fitness outcomes, however, this effect does not appear substantial enough to account for men's near universal tendency to stay within marriages after more than two children have been born (Winking, Kaplan, et al., 2009). Here, we showed that the impacts of father presence on the success of surviving children as adults does not offer much explanatory power either. With only one significant finding out of ten tests, there does not appear to be a substantial association between father death and children's completed growth or reproduction. We argue that outcomes other than enhanced offspring wellbeing, such as increased family production and fertility, as well as social constraints, such as female choice and availability of alternative partners, may better explain the observed patterns among the Tsimane. Future research will be required to assess the validity of such arguments.

\section{Acknowledgments}

This research was supported by the following grants: NSF BCS-0136274, NIH/NIA 1R01AG024119-01. This research was conducted under UNM IRB protocol 20112. We are very grateful to the many colleagues who helped collect and enter the data used here. We would also like to thank the members of the communities in which we worked for their wonderful hospitality and cooperative spirit. 


\section{References}

Alvarez HP. Grandmother hypothesis and primate life histories. American Journal of Physical Anthropology. 2000; 118:435-450. [PubMed: 11042542]

Amato PR. Explaining the intergenerational transmission of divorce. Journal of Marriage and the Family. 1996; 58(3):628-640. Article.

Anderson KG, Kaplan H, Lam D, Lancaster J. Paternal care by genetic fathers and stepfathers II: reports by Xhosa high school students. Evolution and Human Behavior. 1999; 20:433-451.

Apostolou M. Bridewealth and brideservice as instruments of parental choice. Journal of Social, Evolutionary, and Cultural Psychology. 2008; 2(3):89-102.

Belsky J, Steinberg L, Draper P. Childhood experience, interpersonal development, and reproductive strategy: An evolutionary-theory of socialization. Child Development. 1991; 62(4):647-670. Article. [PubMed: 1935336]

Bleige Bird R, Smith EA, Bird DW. The hunting handicap: costly signaling in human foraging strategies. Behavioral Ecology and Sociobiology. 2001; 50:9-19.

Blurton Jones, NG.; Marlowe, F.; Hawkes, K.; O'connel, JF. Paternal investment and hunter-gatherer divorce rates. In: Lee Cronk, NC.; Irons, William, editors. Adaptation and Human Behavior: An Anthropological Perspective. Aldine; New York: 2000. p. 69-90.

Borgerhoff Mulder M. Serial Monogamy as Polygyny or Polyandry? Human Nature-an Interdisciplinary Biosocial Perspective. 2009; 20(2):130-150. Article.

Bumpass LL, Martin TC, Sweet JA. The impact of family background and early marital factors on marital disruption. Journal of Family Issues. 1991; 12(1):22-42. [PubMed: 12316638]

Charnov EL, Berrigan D. Why do female primates have such long lifespans and so few babies? or Life in the slow lane. Evolutionary Anthropology. 1993; 1:191-194.

Cherlin AJ, Chase-Lansdale PL, McRae C. Effects of parental divorce on mental health throughout the life course. American Sociological Review. 1998; 63(2):239-249. Article.

Cohen J. A power primer. Quantitative Methods in Psychology. 1992; 112(1):155-159.

Ellis BJ. Timing of pubertal maturation in girls: An integrated life history approach. Psychological Bulletin. 2004; 130(6):920-958. [PubMed: 15535743]

Flinn MV. Step- and genetic parent/offspring relationships in a Caribbean vilage. Ethology and Sociobiology. 1988; 9:335-369.

Foster Z, Byron E, Reyes-Garcia V, Huanca T, Vadez V, Apaza L, et al. Physical growth and nutritional status of Tsimane' Amerindian children of lowland Bolivia. American Journal of Physical Anthropology. 2005; 126(3):343-351. [PubMed: 15386291]

Gettler L. Direct male care and hominin evolution. American Anthropologist. 2010; 112(1):7-21.

Gurven M, Hill K. Hunting as subsistence and mating effort? A re-evaluation of "Man the Hunter", the sexual division of labor and the evolution of the nuclear family. Current Anthropology. 2009; 50(1):51-74. [PubMed: 19579355]

Gurven M, Kaplan H, Zelada Supa A. Mortality experience of Tsimane Amerindians: regional variation and temporal trends. American Journal of Human Biology. 2007; 19:376-398. [PubMed: 17421012]

Gurven M, Winking J, Kaplan H, von Rueden C, McAllister L. A bioeconomic approach to marriage and the sexual division of labor. Human Nature. 2009; 20(2):151-183.

Hagen EH, Hames RH, Craig NM, Lauer M. t. Price ME. Parental investment and child health in a Yanomamo village suffering short-term food stress. Journal of Biosocial Science. 2001; 33:505528.

Hames R, Oliver WJ, Chagnon NA. Growth, development, and health of Yanomamö orphans in relation to parental loss. no date.

Hartung J. Polygyny and inheritance of wealth. Current Anthropology. 1982; 23(1):1-11. Article.

Hawkes K. Showing off: Tests of an hypothesis about men's foraging goals. Ethology and Sociobiology. 1991; 12(1):29-54.

Hawkes K. Why hunter-gatherers work. Current Anthropology. 1993; 34(4):341-361. 
Hawkes K, Rogers AR, Charnov EL. The male's dilemma: increased offspring production is more paternity to steal. Evolutionary Ecology. 1995; 9:662-677.

Hewlett, BS. Intimate Fathers: The Nature and Context of Aka Pygmy Paternal Infant Care. The University of Michigan Press; Ann Arbor: 1992.

Hill, K.; Hurtado, AM. Ache Life History: The Ecology and Demography of a Foraging People. Aldine; New York: 1996.

Hurtado AM, Hill K, Kaplan H, Hurtado I. Trade-offs between female food acquisition and child care among Hiwi and Ache foragers. Human Nature. 1992; 3(3):185-216.

Hurtado, AM.; Hill, KR. Paternal effect on offspring survivorship among Ache and Hiwi huntergatherers: Implications for modeling pair-bond stability. In: Hewlett, BS., editor. Father-Child Relations: Cultural and Biosocial Contexts. Aldine; Chicago: 1992. p. 31-55.

Kaplan H, Gurven M, Winking J, Hooper P, Stieglitz J. Learning, menopause and the human adaptive complex. Annals of the New York Academy of Sciences. In press.

Kaplan, HS.; Lancaster, JB. An evolutionary and ecological analysis of human fertility, mating patterns, and parental investment. In: Wachter, KW.; Bulatao, RA., editors. Offspring: Human Fertility Behavior in Biodemographic Perspective. National Academies Press; Washington, D.C.: 2003. p. 170-223.

Kleiman, DG.; Malcolm, JR. The evolution of male parental investment in mammals. In: Gubernick, DJ.; Klopfer, PH., editors. Parental Care in Mammals. Plenum Press; New York: 1981. p. 347-387.

Lamb, ME. Fathers and child development: An introductory overview and guide. In: Lamb, ME., editor. The role of the father in child development. 3rd edition. Wiley; New York: 1997.

Lancaster, JB.; Lancaster, CS. Parental investment: the hominid adaptation. In: Ortner, DJ., editor. How Humans Adapt: A biocultural Odyssey. Smithsonian Institution Press; Washington, D.C.: 1983. p. 33-69.

Lang K, Zagorsky JL. Does growing up with a parent absent really hurt? Journal of Human Resources. 2001; 36(2):253-273.

Lazarus J. The logic of mate desertion. Animal Behavior. 1990; 39:672-684.

Lee RD, Kramer KL. Children's economic roles in the Maya family life cycle: Cain, Caldwell and Chayanov revisited. Population and Development Review. 2002; 28(3):475-499.

Lovejoy O. The origin of man. Science. 1981; 211:341-350. [PubMed: 17748254]

Marlowe F. Paternal investment and the human mating system. Behavioural Processes. 2000; 51:4561. [PubMed: 11074311]

Marlowe F. A critical period for provisioning by Hadza men: Implications for pair bonding. Evolution and Human Behavior. 2003; 24:217-229.

Marlowe, FW. Who tends Hadza children?. In: Hewlett, B.; Lamb, M., editors. Hunter-Gatherer Childhoods: Evolutionary, Developmental and Cultural Perspectives. Transaction; New Brunswick: 2005. p. 177-190.

Maynard Smith J. Parental investment: a prospective analysis. Animal Behavior. 1977; 25:1-9.

McLanahan, SS.; Sandefur, B. Growing Up with a Single Parent: What Hurts, What Helps?. Harvard University Press; Cambridge, MA: 1994.

Nystrom Peck M, Lundberg O. Short Stature as an Effect of Economic and Social Conditions in Childhood. Social Science \& Medicine. 1995; 41(5):733-738. [PubMed: 7502105]

Pedersen FA. Secular trends in human sex ratios: Their influence on individual and family behavior. Human Nature. 1991; 2(3):271-291.

Plavcan JM, Lockwood CA, Kimbel WH, Lague MR, Harmon EH. Sexual dimorphism in Australopithecus afarensis revisited: How strong is the case for a human-like pattern of dimorphism? Journal of Human Evolution. 2005; 48(3):313-320. [PubMed: 15737396]

Plavcan JM, Van Schaik CP. Interpreting hominid behavior on the basis of sexual dimorphism. Journal of Human Evolution. 1997; 32(4):345-374. [PubMed: 9085186]

Powell MA, Parcel TL. Effects of family structure on the earnings attainment process: Differences by gender. Journal of Marriage and the Family. 1997; 59(2):419-433. 
Quinlan RJ. Human pair-bonds: Evolutionary functions, ecological variation, and adaptive development. Evolutionary Anthropology. 2008; 17(5):227-238.

Quinlan RJ, Quinlan MB. Evolutionary ecology of human pair-bonds - Cross-cultural tests of alternative hypotheses. Cross-cultural Research. 2007; 41(2):149-169.

Scelza BA. Fathers' presence speeds the social and reproductive careers of sons. Current Anthropology. 2010; 51(2):295-303.

Schmitt DP. Sociosexuality from Argentina to Zimbabwe: A 48-nation study of sex, culture, and strategies of human mating. Behavioral and Brain Sciences. 2005; 28(2):247-275. [PubMed: 16201459]

Schniter, E. Dissertation. University of California at Santa Barbara; 2009. Why Old Age: Non-material Contributions and Patterns of Aging among Older Adult Tsimane.

Sear, R.; Allal, N.; Mace, R. Height, marriage and reproductive success in Gambian women. In: Alvard, MS., editor. Socioeconomic Aspects of Human Behavioral Ecology. Vol. Vol. 23. JaiElsevier Sci Bv; Amsterdam: 2004. p. 203-224.

Sear R, Mace R. Who keeps children alive? A review of the effects of kin on child survival. Evolution and Human Behavior. 2008; 29(1):1-18.

Sear R, Mace R, McGregor IA. Maternal grandmothers improve the nutritional status and survival of children in rural Gambia. Proceedings of the Royal Society of London B Biological Sciences. 2000; 267:1641-1647.

Silventoinen K, Kaprio J, Lahelma E, Koskenvuo M. Relative effect of genetic and environmental factors on body height: Differences across birth cohorts among Finnish men and women. American Journal of Public Health. 2000; 90(4):627-630. [PubMed: 10754982]

Smith CC, Fretwell SD. The optimal balance between size and number of offspring. The American Naturalist. 1974; 108(962):499-506.

Trent K, South S. Structural determinants of divorce rate: A cross-societal analysis. Journal of Marriage and the Family. 1989; 51:391-404.

Trivers, RL. Parental investment and sexual selection. In: Campbell, B., editor. Sexual Selection and the Descent of Man. Aldine; Chicago: 1972. p. 1871-1971.

van Schaik CP, Paul A. Male care in primates: does it ever reflect paternity? Evolutionary Anthropology. 1996; 5:152-156.

Winking J. Are men that bad as fathers? The role of men's investments. Social Biology. 2006; 53(1-2): $100-115$.

Winking J, Gurven M, Kaplan H. The impacts of parents and self selection on child survival among the Tsimane of Bolivia. n.d.

Winking J, Gurven M, Kaplan H, Stieglitz J. The goals of direct paternal care among a South Amerindian population. American Journal of Physical Anthropology. 2009; 139(3):295-304. [PubMed: 19140194]

Winking, J.; Kaplan, H.; Gurven, M. Patterns of divorce and remarriage among Tsimane men. Annual Meeting of the American Anthropological Association; Philadelphia, Pennsylvania. 2009.

Winking J, Kaplan H, Gurven M, Rucas S. Why do men marry and why do they stray? Proceedings of the Royal Society of London B: Biological Sciences. 2007; 274(1618):1643-1649. 


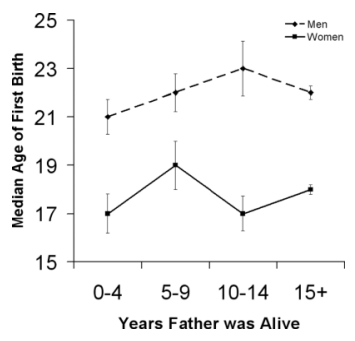

Figure 1.

Median age of first birth by the number of years the father was alive during childhood for men and women.

Sample sizes for sons are 17, 16, 19 and 405 for the age brackets $0-4,5-9,10-14$ and 15+ respectively. For daughters, these numbers are 20, 17, 23 and 409. Error bars represent standard errors. 


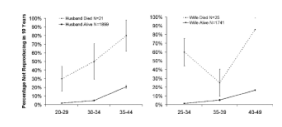

Figure 2.

Probability of failing to reproduce within 10 years of last birth by whether spouse has died within 3 years of last birth. 


\section{Table 1}

Impacts of father and mother death on child mortality

\begin{tabular}{lllll} 
& Child Mortality $<\mathbf{1}$ & Child Mortality $<5$ & Child Mortality $<\mathbf{1 0}$ & Child Mortality $<\mathbf{1 5}$ \\
\hline Mother Death & $\mathbf{O R}=\mathbf{1 6 8 . 5 9 5} b$ & $\mathbf{O R}=\mathbf{7 . 8 5 3}$ & $\mathbf{O R}=\mathbf{6 . 8 5 1}$ & $\mathbf{O R}=\mathbf{4 . 6 2 6}$ \\
& $\mathrm{p}<0.001$ & $\mathrm{p}<0.001$ & $\mathrm{p}<0.001$ & $\mathrm{p}<0.001$ \\
& $\mathrm{n}_{\mathrm{p}}=4528(358)^{a}$ & $\mathrm{n}_{\mathrm{p}}=4329(560)$ & $\mathrm{n}_{\mathrm{p}}=4072(643)$ & $\mathrm{n}_{\mathrm{p}}=3889(684)$ \\
& $\mathrm{n}_{\mathrm{a}}=21(9)$ & $\mathrm{n}_{\mathrm{a}}=92(15)$ & $\mathrm{n}_{\mathrm{a}}=181(25)$ & $\mathrm{n}_{\mathrm{a}}=240(29)$ \\
\hline Father Death & $\mathrm{OR}=9.721$ & $\mathbf{O R}=\mathbf{2 . 9 6 0}$ & $\mathrm{OR}=1.970$ & $\mathrm{OR}=1.494$ \\
& $\mathrm{p}=0.153$ & $\mathrm{p}=0.041$ & $\mathrm{p}=0.163$ & $\mathrm{p}=0.350$ \\
& $\mathrm{n}_{\mathrm{p}}=4532(358)$ & $\mathrm{n}_{\mathrm{p}}=4329(560)$ & $\mathrm{n}_{\mathrm{p}}=4072(643)$ & $\mathrm{n}_{\mathrm{p}}=3889(684)$ \\
& $\mathrm{n}_{\mathrm{a}}=19(4)$ & $\mathrm{n}_{\mathrm{a}}=82(8)$ & $\mathrm{n}_{\mathrm{a}}=181(12)$ & $\mathrm{n}_{\mathrm{a}}=257(15)$ \\
\hline
\end{tabular}

Reprinted from (Winking, et al. n.d.). Controls include community region, birth order, sex and a random family term.

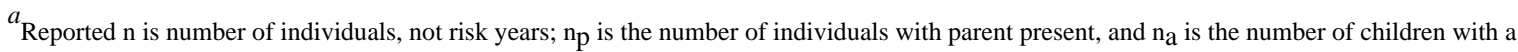
parent absent. Numbers within parentheses indicate the number of individuals within that group who died.

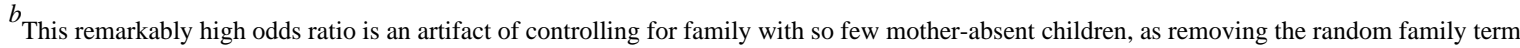
resulted in an odds ratio of $6.011(\mathrm{p}<0.001)$. 


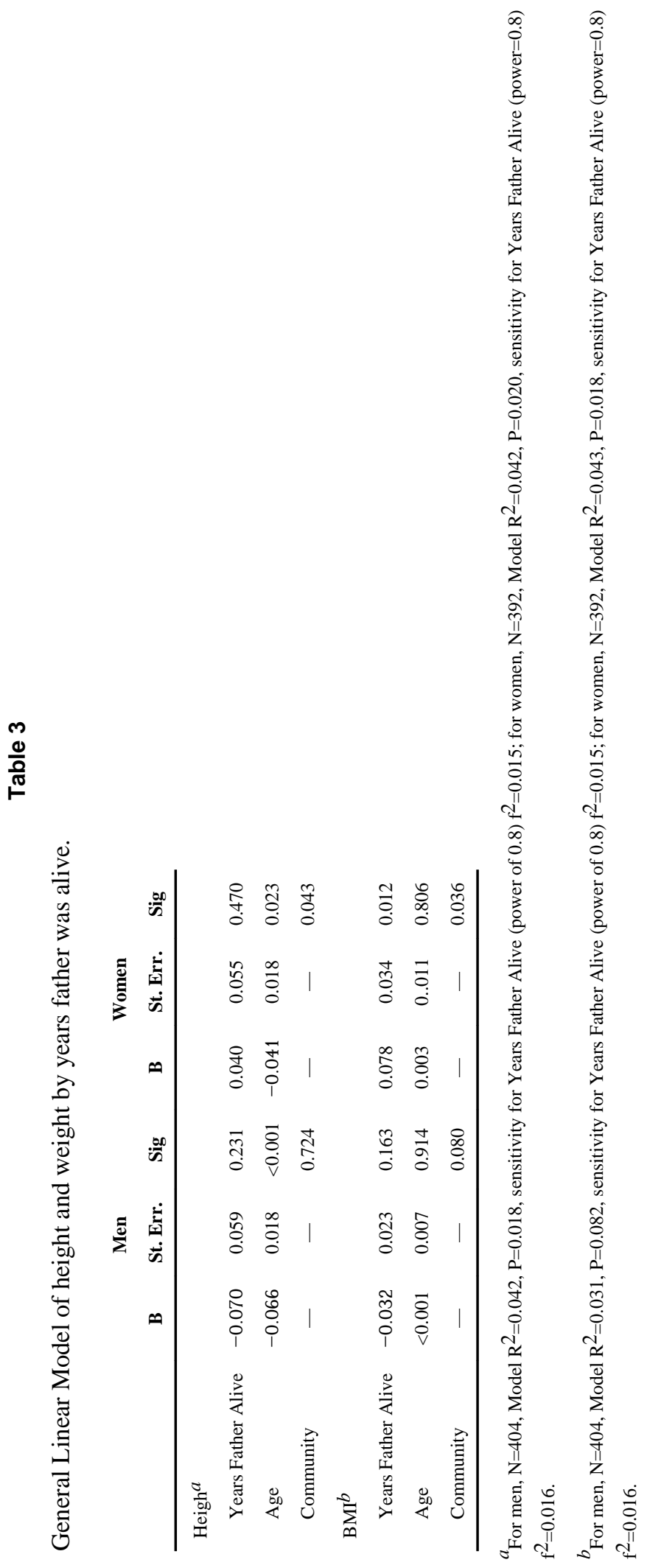

Evol Hum Behav. Author manuscript; available in PMC 2012 March 1. 


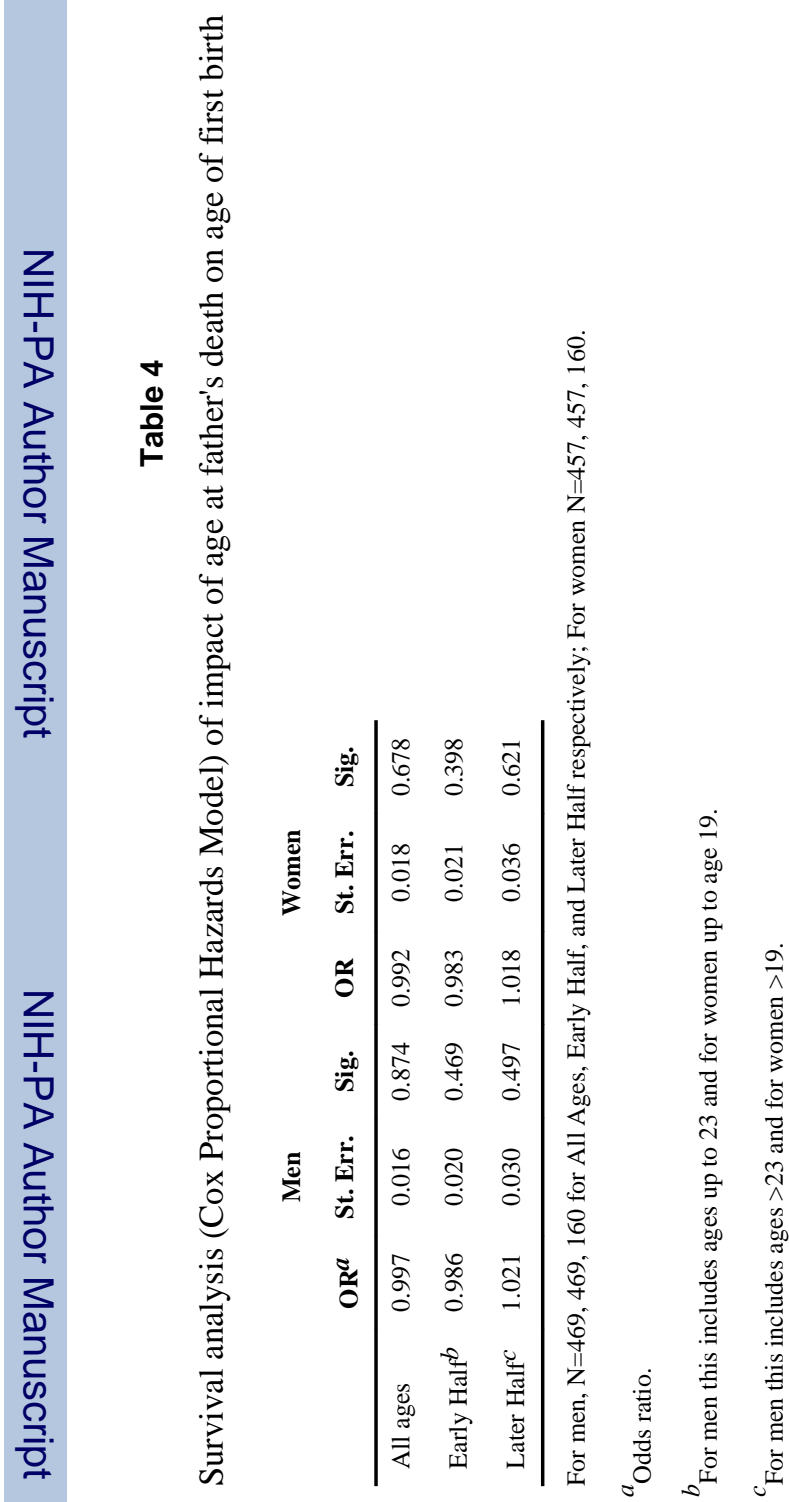




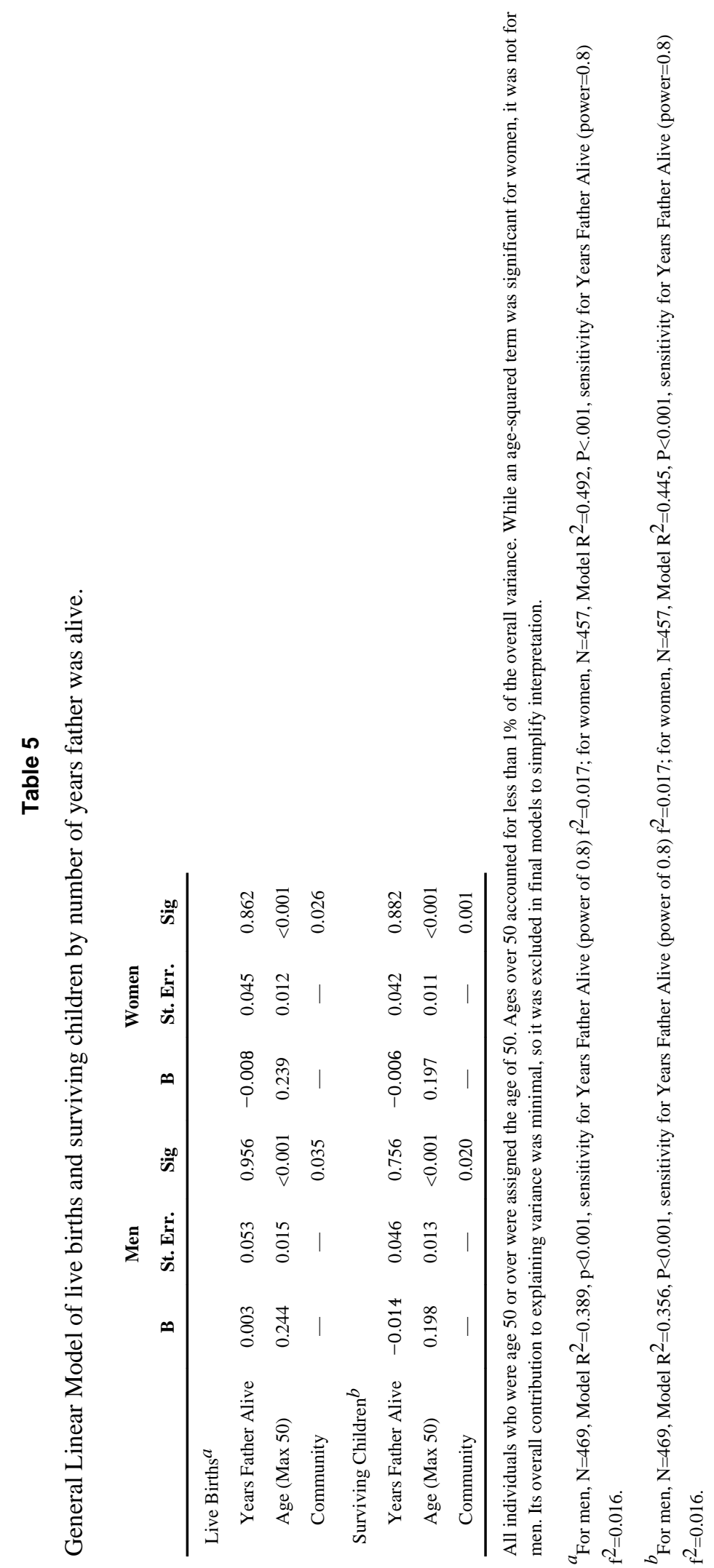

Evol Hum Behav. Author manuscript; available in PMC 2012 March 1. 